\title{
Abnormal expression levels of sMICA and NKG2D are correlated with poor prognosis in pancreatic cancer
}

This article was published in the following Dove Press journal:

Therapeutics and Clinical Risk Management

22 December 2015

Number of times this article has been viewed

\author{
Jiong Chen ${ }^{1,2, *}$ \\ Hong $X u^{1,2, *}$ \\ Xing-Xing Zhu ${ }^{1,2}$ \\ 'Department of General Surgery, \\ Affiliated Provincial Hospital, \\ Anhui Medical University, ${ }^{2}$ Anhui \\ Province Key Laboratory of \\ Hepatopancreatobiliary Surgery, \\ Hefei, People's Republic of China \\ *These authors contributed equally \\ to this work
}

\begin{abstract}
Soluble major histocompatibility complex class I-related chain A molecules (sMICA) and natural-killer group 2 member D (NKG2D) not only correlate with tumorigenesis and progression, but also with tumor invasion and metastasis. In this study, we used immunohistochemistry to investigate the correlation and prognostic significance of the differential expression of sMICA and NKG2D in pancreatic carcinoma and paracarcinoma tissues from 70 patients with pancreatic carcinomas. The results showed that sMICA expression was significantly $(P<0.05)$ higher in tumor tissues (67.1\%) than that in adjacent nontumor tissues (31.4\%), whereas NKG2D expression was significantly $(P<0.001)$ lower in tumor tissues $(32.9 \%)$ than that in adjacent nontumor tissues $(60.0 \%)$. Spearman's rank correlation test showed a negative correlation between the expression of sMICA and that of NKG2D ( $r=-0.676, P<0.001)$. Kaplan-Meier survival analysis showed that a high sMICA expression was significantly correlated with decreased disease-free survival (DFS) $(P<0.001)$ and overall survival (OS) $(P<0.001)$, while a high NKG2D expression was significantly associated with increased DFS $(P=0.001)$ and OS $(P=0.001)$ of the patients. Multivariate analysis showed that a high sMICA expression was an independent predictive factor for poor DFS $(P<0.001)$ and OS $(P=0.012)$; but low NKG2D expression was not an independent prognostic factor for poor DFS $(P=0.238)$ and $\mathrm{OS}(P=0.574)$. In conclusion, our findings suggest that the expression levels of sMICA and NKG2D are abnormal and negatively correlated with one another in pancreatic carcinoma tissues; they may be considered as valuable biomarkers for the prognosis of pancreatic carcinoma.
\end{abstract}

Keywords: pancreatic carcinoma, immunohistochemistry, biomarkers

\section{Introduction}

Pancreatic cancer manifests itself as a malignant and highly aggressive digestive system tumor. It is very difficult to diagnose this disease in its early stages when it is just a local invasion, and hence by the time a first diagnosis is made, the cancer has usually metastasized to distant locations, leading to an extremely poor outcome. ${ }^{1,2}$ According to the latest statistics, pancreatic cancer is the ninth most common disease producing malignant tumors and the fourth leading cause of cancer-related deaths worldwide, with a 5 -year survival rate of $<5 \% .{ }^{3}$ It is therefore, important to identify specific tumor markers and search for effective therapeutic methods to improve prognosis of this disease.

Tumor immunotherapy, which is currently a hot topic, has been shown to be able to induce the death of tumor cells by activating immune cells in vitro, thereby enhancing the antitumor ability of the human immune system. ${ }^{4}$ T-cells negative for $\mathrm{CD}^{-}{ }^{-}$and CD8-, termed "double negative T (DNT) cells", constitute a subgroup of T-cells associated with an immunosuppression regulating function that can kill tumor cells. ${ }^{5}$ Previous research has shown that DNTs have an inhibitive effect on the proliferation
Correspondence: Jiong Chen Department of General Surgery, Affiliated Provincial Hospital, Anhui Medical University, 17 Lujiang Road, Hefei 23000I, Anhui Province, People's Republic of China

Email chen_jiong@।26.com
Therapeutics and Clinical Risk Management 2016:12 II-18 cc) (i) (5) 2016 Chen et al. This work is published and licensed by Dove Medical Press limited. The full terms of this license are available at https://www.dovepress.com/terms.php and incorporate the Creative Commons Attribution - Non Commercial (unported, v3.0) License (http://(creativecommons.org//icenses/by-nc/3.0/). By accessing the work you ermission from Dove Medical Press Limited, provided the work is properly attributed. For permission for commercial use of this work, please see paragraphs 4.2 and 5 of our Terms (https://www.dovepress.com/terms.php). 
of tumor cells. Li et $\mathrm{al}^{6}$ reported that DNT cells can regulate tumor immune response by inhibiting B-cell hyperplasia and immunoglobulin production in vitro. Dokouhaki et $\mathrm{al}^{7}$ suggested that DNT cells participate in killing tumor cells by using natural-killer group 2 member D (NKG2D). NKG2D is an activated receptor expressed in macrophages, nationalkiller cells, and $\gamma \delta$ T-cells, and contains two $\alpha$ helices, two $\beta$ sheets, and four disulfide bonds, and its amino terminal region is composed of an amino arm, ring, and $\beta$ substring. ${ }^{8}$ NKG2D can activate the human immune system through identifying target cell surface activation induced related ligand to transmit signals, thereby having an antitumor effect on its target. The molecular ligands of NKG2D include major histocompatibility complex class I-related chain A molecules (MICA), MHC class I-related chain B (MICB), and link protein, ${ }^{9,10}$ and they play an important role in immune surveillance of tumor cells. ${ }^{11}$

MICA is a transmembrane glycoprotein that is the main ligand of NKG2D ligands. MICA is made up of three extracellular regions ( $\alpha 1, \alpha 2$, and $\alpha 3)$, a transmembrane region, and a cytoplasmic tail region. In the early stages of tumor progression, MICA is highly expressed in the cell membrane. As the tumor progression continues, the expression of MICA is gradually reduced in the cell membrane, ${ }^{12}$ and then MICA is transferred to the cytoplasm to become soluble MICA (sMICA).

The current study set out to determine the levels of sMICA and NKG2D expression in pancreatic cancer tissues and their corresponding paracarcinoma tissue using immunohistochemistry, and to explore the relationships between these expression levels and clinicopathological parameters, and postoperative survival time in patients with pancreatic cancer.

\section{Materials and methods Patients and samples}

This study was approved by the Human Scientific Ethics Committee of Anhui Medical University (Hefei, People's Republic of China). All specimens were obtained from a total of 70 patients who underwent curative resection and were pathologically diagnosed with pancreatic cancer between July 2008 and July 2013 at the Affiliated Provincial Hospital of Anhui Medical University (Hefei, People's Republic of China). Specimens included pancreatic cancer tissues and their corresponding paracarcinoma tissues (defined as pancreatic tissue $>1 \mathrm{~cm}$ from the tumor margin). All patients provided written informed consent, and did not have preoperative chemotherapy and/or radiotherapy.
Clinicopathological data were obtained from medical records and included age, sex, tumor diameter, tumor location, preoperative serum carbohydrate antigen 19-9 (CA19-9) concentrations, tumor differentiation, lymph node metastasis (LNM), and perineural invasion (PNI). The patients consisted of 37 males and 33 females, with a mean age of 56 years (ranging from 46 to 66 years old). The tumor stage was determined according to the tumor-node-metastasis (TNM) classification criteria of the International Association of Cancer. ${ }^{13}$ The disease-free survival (DFS) and overall survival (OS) were investigated to evaluate the influence of NKG2D and sMICA on the prognosis of patients with pancreatic carcinomas. Follow-up data were available for all patients. Mean follow-up was 16 months (ranging from 5 to 28 months).

\section{Immunohistochemical staining for NKG2D and sMICA}

Serial sections of each pathological specimen with a thickness of $5 \mu \mathrm{m}$ were heated at $60^{\circ} \mathrm{C}$ for 30 minutes, dewaxed with xylene, rehydrated with ethanol, and washed with phosphate-buffered saline. Antigen repair was then performed using microwave heating in sodium citrate buffer (pH 6.0) at $80^{\circ} \mathrm{C}$ for 20 minutes. Endogenous peroxidase activity was eliminated by applying 3\% hydrogen peroxide. Subsequently, the sections were incubated with polyclonal mouse anti-MICA (Santa Cruz Biotechnology, Inc, Santa Cruz, CA, USA) or anti-NKG2D (Santa Cruz Biotechnology, Inc, Santa Cruz, CA, USA) at $4{ }^{\circ} \mathrm{C}$ overnight. After washing with phosphate-buffered saline, the sections were incubated with biotinylated secondary mouse antibody and then with horseradish peroxidase-labeled streptavidin for 30 minutes at $37^{\circ} \mathrm{C}$. Chromogenic immunolocalization was implemented by using 3,3'-Diaminobenzidine (Zhongshan Golden Bridge Biotechnology Co, Ltd., Beijing, People's Republic of China). Finally, the sections were successively counterstained with hematoxylin, dehydrated, and mounted. The negative controls were set by omitting the primary antibodies.

Expression of sMICA and NKG2D was semi-quantitatively evaluated according to percentage and intensity of the stained cells. ${ }^{14}$ The percentage of stained cells was graded as follows: 0 points for no staining, 1 point for $1 \%-10 \%$ staining, 2 points for $11 \%-50 \%$ staining, and 3 points for $>50 \%$ staining. The intensity of the stained cells was scored as follows: 0 points for no intensity, 1 point for pale yellow, 2 points for yellow, and 3 points for tan. The final score was calculated by multiplying the scores for the percentage and intensity of the stained cells, and a final score of $\geq 4$ was considered to 
be indicative of high expression, and $<4$ was considered low expression. All sections were assessed independently by two experienced pathologists who were not aware of each other's assessments. A consensus was reached by joint evaluation for all differences.

\section{Statistical analysis}

Statistical analyses were performed using SPSS 17.0 software (SPSS, Inc., Chicago, IL, USA). Immunohistochemical results were analyzed by using the Pearson's chi-square test or Fisher's exact test, based on the total scores. The correlation between sMICA and NKG2D was analyzed by using the Spearman's rank correlation coefficient or Pearson's correlation coefficient. Survival curves were plotted by employing the Kaplan-Meier method, and the differences in survival time were compared by applying the log-rank test. Multivariate analysis was implemented by using the Cox proportional hazards regression model to determine independent prognostic factors that were significant in a univariate Kaplan-Meier analysis. All tests were two-sided and $P<0.05$ was considered statistically significant.
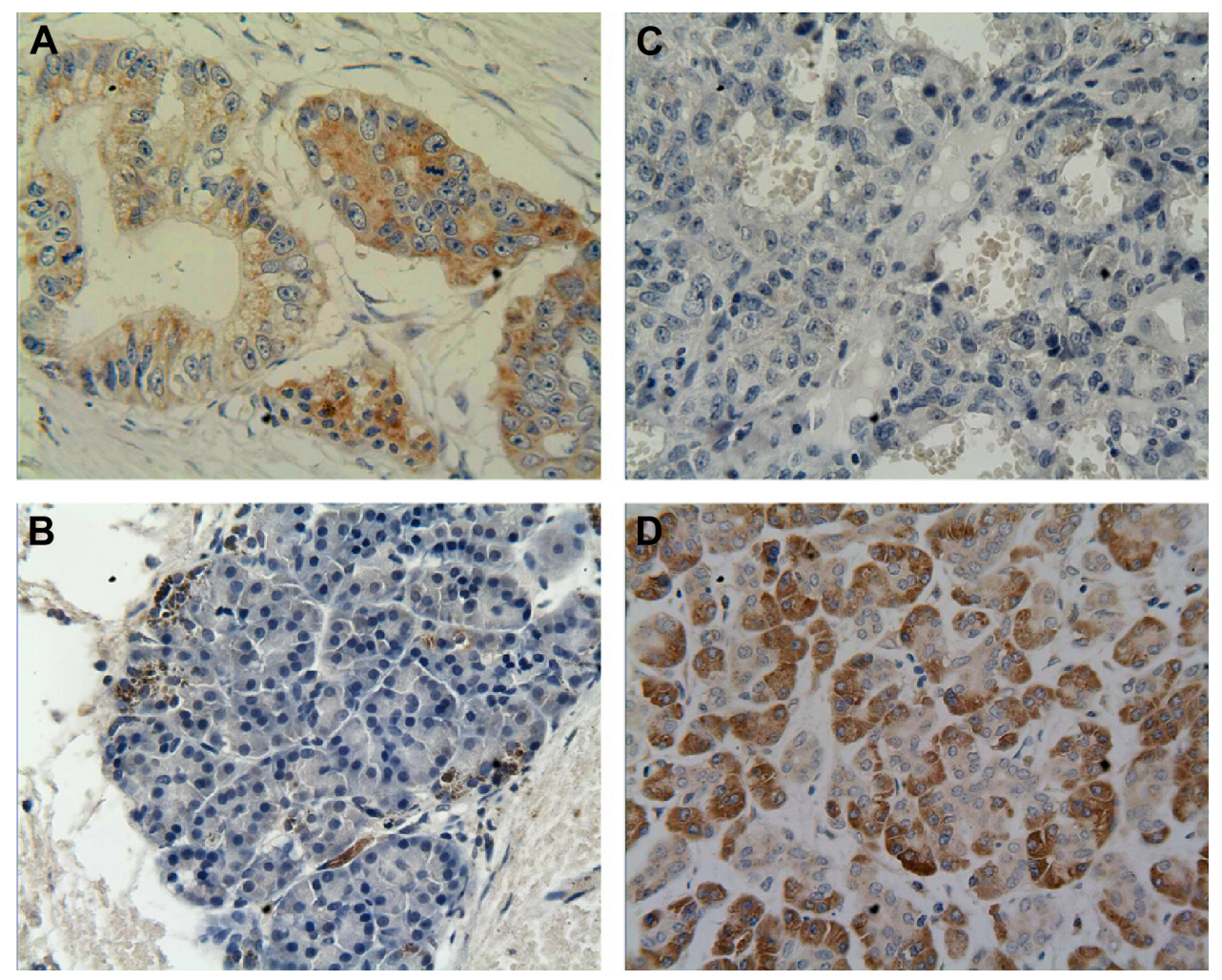

Figure I Immunohistochemical staining for secreted MICA and NKG2D.

Notes: The secreted MICA and NKG2D were principally localized in the cytoplasm of the cells. (A) High expression of secreted MICA was observed in pancreatic carcinoma tissues. (B) Low expression of secreted MICA was observed in paracarcinoma tissues. (C) Low NKG2D expression in pancreatic carcinoma tissues. (D) High NKG2D expression in paracarcinoma tissues. All images were taken at $400 \times$ magnification.

Abbreviations: MICA, major histocompatibility complex class I-related chain A molecules; NKG2D, natural-killer group 2 member D. 
Table I Differential expression of NKG2D and MICA in pancreatic carcinoma tissues and corresponding paracarcinoma tissues ( $\mathrm{N}=70$ )

\begin{tabular}{|c|c|c|c|c|c|c|}
\hline \multirow[t]{2}{*}{ Tissues } & \multicolumn{3}{|l|}{ MICA } & \multicolumn{3}{|l|}{ NKG2D } \\
\hline & Low (\%) & High (\%) & $P$-value & Low (\%) & High (\%) & $P$-value \\
\hline Carcinoma tissues & $23(32.9)$ & $47(67.1)$ & 0.002 & $47(67.1)$ & $23(32.9)$ & 0.013 \\
\hline Paracarcinoma tissues & $48(68.6)$ & $22(3 \mid .4)$ & & $28(40.0)$ & $42(60.0)$ & \\
\hline
\end{tabular}

Abbreviations: MICA, major histocompatibility complex class I-related chain A molecules; NKG2D, natural-killer group 2 member D.

preoperative serum CA19-9 $(P=0.001)$ levels than in those without. In contrast, NKG2D expression showed a lower level in patients with poor tumor differentiation $(P<0.001)$, LNM $(P<0.001)$, PNI $(P<0.001)$, high tumor stage $(P<0.001)$, and high preoperative serum CA19-9 $(P=0.004)$ levels than in those without. However, there was no significant association between sMICA or NKG2D and other clinicopathological parameters, including age, sex, tumor location, and tumor diameter $(P>0.05)$. The results are shown in Table 3.

\section{Survival analysis}

Kaplan-Meier analysis showed that a high sMICA expression was correlated with a significantly shorter survival time (mean DFS: 10.9 months, mean OS: 16.4 months) compared with a low sMICA expression (mean DFS: 20.8 months, mean OS: 21.2 months) in patients with pancreatic carcinoma $(P<0.001$ for DFS and OS; Figure $2 \mathrm{~A}$ and $\mathrm{B})$. Conversely, the patients with a high NKG2D expression had a significantly longer survival time ( $P=0.001$ for DFS and OS; Figure $2 \mathrm{C}$ and D) than those with a low NKG2D expression. Mean DFS was 18.7 months for a high NKG2D expression, and 11.9 months for a low NKG2D expression; mean OS was 20.3 months for a high NKG2D expression, and 16.5 months for a low NKG2D expression.

Univariate analysis (Table 4) indicated that a high sMICA expression, low NKG2D expression, high serum CA19-9, poor tumor differentiation, LNM, PNI, and a high tumor stage were significantly associated with a poor prognosis. Multivariate analysis (Table 5) further indicated that high sMICA expression was an independent prognostic factor for poor DFS (hazard ratio $=7.785 ; 95 \%$ confidence interval:

Table 2 Correlation between MICA and NKG2D expression $(\mathrm{N}=70)$

\begin{tabular}{lllll}
\hline Immunoreactivity & \multicolumn{4}{c}{ NKG2D expression } \\
\cline { 2 - 5 } & Low & High & r-value & P-value \\
\hline MICA expression & 5 & 18 & -0.676 & $<0.001$ \\
Low & 42 & 5 & & \\
High & 42 & & & \\
\hline
\end{tabular}

Abbreviations: MICA, major histocompatibility complex class I-related chain $A$ molecules; NKG2D, natural-killer group 2 member D.
3.247-18.666; $P<0.001$ ) and OS (hazard ratio $=3.853 ; 95 \%$ confidence interval: $1.345-11.041 ; P=0.012)$. However, the low NKG2D expression was not an independent predictor for poor DFS $(P=0.238)$ and $\mathrm{OS}(P=0.574)$. Additionally, poor tumor differentiation and high tumor stage were independent predictors for poor prognosis.

\section{Discussion}

This study investigated the levels of sMICA and NKG2D expression, and analyzed their relationships with clinicopathological characteristics and prognosis in pancreatic cancer. The results showed that sMICA expression was higher in tumor tissues than in surrounding nontumor tissues. NKG2D expression was lower in tumor tissues than in surrounding nontumor tissues. SMICA expression had a negative correlation with NKG2D expression in tumor tissues. sMICA and NKG2D expression in tumor tissues were, respectively, significantly positively and significantly negatively correlated with several aggressive clinicopathological characteristics, such as poor tumor differentiation, high preoperative serum CA19-9 levels, LNM, PNI, and high tumor stage. High sMICA expression and low NKG2D expression in tumor tissues were significantly associated with poor DFS and OS of patients.

There is an increasing amount of evidence of a significant role for MICA in tumor invasion and metastasis. In a previous study, sMICA expression was observed to be higher in pancreatic tumor cells than in normal pancreatic ductal epithelial cells, and increased sMICA expression was clearly correlated with poor tumor differentiation and LNM. ${ }^{15}$ In another study by Cho et al, ${ }^{16}$ sMICA expression was shown to be higher in cervical cancer tissue than in low-grade cervical intraepithelial neoplasia and normal cervix.

Two types of MICA have been found to be associated with the rapid development of tumors: ${ }^{17}$ in the early stage, MICA is expressed in the membrane, but with tumor progression, membrane MICA is transformed into sMICA in the cytoplasm. ${ }^{18}$ Membrane MICA when combined with NKG2D can activate $\gamma \delta$ T-cells, which induces specific immune cells to kill target tumor cells. ${ }^{19}$ However, sMICA suppresses the level of NKG2D expression, and hence 
Table 3 Relationships of MICA, NKG2D, and clinicopathological parameters of pancreatic cancer

\begin{tabular}{|c|c|c|c|c|c|c|c|c|c|}
\hline \multirow[t]{2}{*}{ Parameters } & \multicolumn{5}{|c|}{ MICA } & \multicolumn{4}{|c|}{ NKG2D } \\
\hline & $\mathbf{N}$ & Low & High & $\chi^{2}$ & $P$-value & Low & High & $\chi^{2}$ & $P$-value \\
\hline \multicolumn{10}{|l|}{ Age (years) } \\
\hline$<60$ & 33 & 14 & 19 & 2.59 & 0.108 & 19 & 14 & 2.59 & 0.108 \\
\hline$\geq 60$ & 37 & 9 & 28 & & & 28 & 9 & & \\
\hline \multicolumn{10}{|l|}{ Sex } \\
\hline Male & 37 & 13 & 24 & 0.185 & 0.667 & 24 & 13 & 0.185 & 0.667 \\
\hline Female & 33 & 10 & 23 & & & 23 & 10 & & \\
\hline \multicolumn{10}{|l|}{ Tumor location } \\
\hline Head & 39 & 16 & 23 & 2.664 & 0.103 & 26 & 13 & 0.009 & 0.924 \\
\hline Body/tail & 31 & 7 & 24 & & & 21 & 10 & & \\
\hline \multicolumn{10}{|l|}{ Tumor diameter } \\
\hline$<20 \mathrm{~mm}$ & 25 & II & 14 & 2.189 & 0.139 & 16 & 9 & 0.174 & 0.676 \\
\hline$\geq 20 \mathrm{~mm}$ & 45 & 12 & 33 & & & 31 & 14 & & \\
\hline \multicolumn{10}{|l|}{ Histological grade } \\
\hline Moderate/poor & 48 & 5 & 43 & 34.862 & $<0.001$ & 39 & 9 & 13.777 & $<0.001$ \\
\hline Well & 22 & 18 & 4 & & & 8 & 14 & & \\
\hline \multicolumn{10}{|l|}{ Perineural invasion } \\
\hline Absent & 25 & 18 & 7 & 27.009 & $<0.001$ & 12 & 13 & 6.460 & 0.011 \\
\hline Present & 45 & 5 & 40 & & & 35 & 10 & & \\
\hline \multicolumn{10}{|l|}{ LNM } \\
\hline Absent & 28 & 19 & 9 & 25.913 & $<0.001$ & 10 & 18 & 20.894 & $<0.001$ \\
\hline Present & 42 & 4 & 38 & & & 37 & 5 & & \\
\hline \multicolumn{10}{|l|}{ TNM stage } \\
\hline 1 & 28 & 19 & 9 & 25.913 & $<0.001$ & 10 & 18 & 20.894 & $<0.001$ \\
\hline II & 42 & 4 & 38 & & & 37 & 5 & & \\
\hline \multicolumn{10}{|l|}{ Serum CAI9-9 } \\
\hline$\leq 37 \mathrm{U} / \mathrm{mL}$ & 26 & 15 & 11 & 11.564 & 0.001 & 12 & 14 & 8.26 & 0.004 \\
\hline$>37 \mathrm{U} / \mathrm{mL}$ & 44 & 8 & 36 & & & 35 & 9 & & \\
\hline
\end{tabular}

Abbreviations: CAI9-9, carbohydrate antigen 19-9; LNM, lymph node metastasis; MICA, major histocompatibility complex class I-related chain A molecules; NKG2D, natural-killer group 2 member D; TNM, tumor-node-metastasis.

weakens the antitumor capabilities of the human immune system. Therefore, membrane MICA is considered to be a tumor inhibitor since it can enhance the antitumor effect of the human immune system. ${ }^{20}$ Moreover, some drugs such as doxorubicin and $\alpha$ interferon have been reported to be able to increase the expression of NKG2D ligands, thereby enhancing the immunocompetence for targeting tumors. ${ }^{21}$

In our study, we investigated the expression characteristics of sMICA and NKG2D in pancreatic carcinoma tissue and paracarcinoma tissue by immunohistochemistry. MICA staining was mainly found in the cytoplasm of pancreatic cancer cells; that is, sMICA was highly expressed in the cytoplasm. Such staining in the cell membrane (for membrane MICA) was not observed, possibly because most of the cases had already reached the advanced tumor stage. Besides, membrane MICA is not always expressed in the early tumor stage in pancreatic cancer. Our findings showed that cytoplasmic sMICA expression was upregulated and NKG2D expression was downregulated in pancreatic carcinoma tissues: that is, sMICA expression was negatively correlated with NKG2D expression in carcinoma tissues. sMICA and NKG2D expression levels in carcinoma tissues were significantly correlated with several aggressive clinicopathological features. These observations suggested that dysregulated expression of sMICA and NKG2D was closely related to the development and progression of pancreatic cancer.

Dambrauskas et $\mathrm{al}^{15}$ have shown that pancreatic carcinoma patients with high sMICA expression levels have shorter long-term survival than those with a low sMICA expression. Duan et $\mathrm{al}^{22}$ reported that pancreatic cancer patients with low serum sMICA levels have a significantly longer mean survival time than those with high serum sMICA levels. $\mathrm{Li}$ et $\mathrm{al}^{23}$ showed that a high serum sMICA level was significantly correlated with poor prognosis in patients with advanced hepatocellular carcinoma. McGilvray et al ${ }^{24}$ revealed an association between NKG2D ligand expression and prognosis in human colorectal cancer. In another study, McGilvray et $\mathrm{a}^{25}$ suggested that NKG2D ligands are independent predictors of poor prognosis in patients with ovarian cancer. In the present study, abnormal expression of NKG2D 

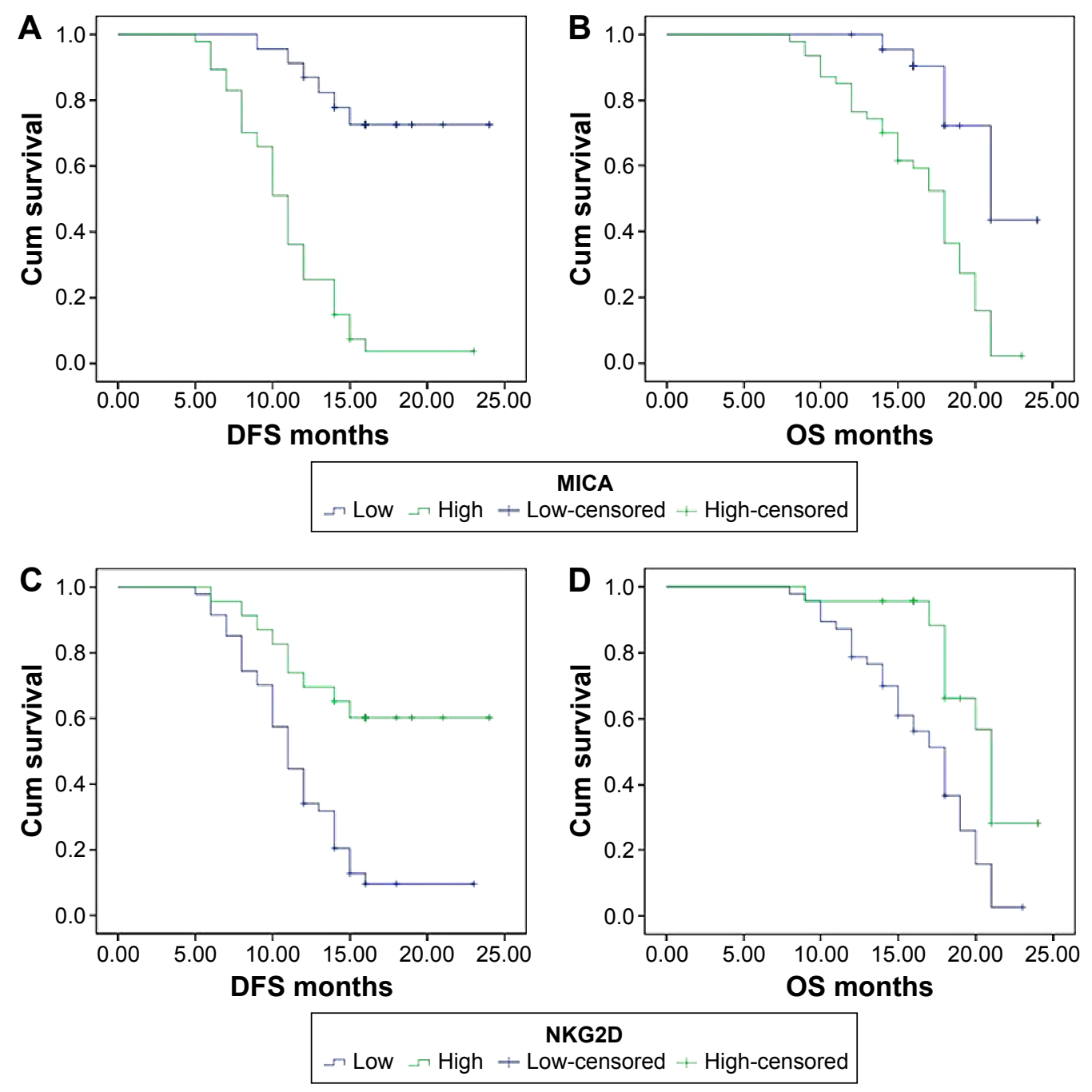

Figure 2 Kaplan-Meier analysis showing the expression levels of MICA and NKG2D.

Notes: Kaplan-Meier analysis shows that a high expression level of MICA (A, B) was significantly associated with a poor disease-free survival (DFS) and overall survival (OS) of patients with pancreatic carcinoma, while a high expression level of NKG2D (C, D) was significantly correlated with improved $D F S$ and $O S$ ( $N=70$; $P<0.00$ I, log-rank test).

Abbreviations: MICA, major histocompatibility complex class I-related chain A molecules; NKG2D, natural-killer group 2 member D.

and SMICA in pancreatic cancer tissues was observed to be associated with a poor prognosis for the patients after their resection operations. High sMICA expression was associated with a reduced DFS and OS compared with a low sMICA expression, whereas a high NKG2D expression was associated with an increased DFS and OS compared with a low NKG2D expression. Moreover, multivariate analysis showed a high sMICA expression to be an independent factor for poor DFS and OS of the pancreatic cancer patients. Low NK2GD expression, however, was not an independent marker for DFS and $O S$ in these patients. High sMICA expression and a low NKG2D expression together was found to have a unfavorable effect on the prognosis of these patients, and this result indirectly shows that their genes may have opposite effects on the progression of pancreatic cancer.
Expression of sMICA and of NKG2D in tumor tissues are associated with poor prognosis, highlighting an important reference value of DNT cells applying to tumor immunotherapy. ${ }^{26-28}$ The antitumor effects of DNT cells have been shown in vitro and in vivo. ${ }^{29-31}$ For instance, Young et $\mathrm{al}^{29}$ showed that DNT cells can inhibit lymphoma growth in mouse models. Dokouhaki et $\mathrm{al}^{30}$ suggested that DNT cells kill tumor cells effectively in the early stages of several kinds of tumors. Similarly, Merims et $\mathrm{al}^{31}$ indicated that DNT cells effectively kill tumor cells in hematological malignancies.

A major limitation of this retrospective research is its relatively small sample size. In addition, this research has not implemented other effective methods such as quantitative polymerase chain reaction and Western blots. Therefore, 
Table 4 Univariate analysis of factors associated with OS and DFS

\begin{tabular}{|c|c|c|c|c|}
\hline \multirow[t]{2}{*}{ Variables } & \multicolumn{2}{|l|}{ OS } & \multicolumn{2}{|l|}{ DFS } \\
\hline & Mean survival time (month) & $P$-value & Mean survival time (month) & $P$-value \\
\hline \multicolumn{5}{|l|}{ MICA } \\
\hline Low & 21.2 & $<0.001$ & 20.8 & $<0.001$ \\
\hline High & 16.4 & & 10.9 & \\
\hline \multicolumn{5}{|l|}{ NKG2D } \\
\hline Low & 16.5 & 0.001 & 11.9 & 0.001 \\
\hline High & 20.3 & & 18.7 & \\
\hline \multicolumn{5}{|l|}{ Age (years) } \\
\hline$<60$ & 18.2 & 0.638 & 15.3 & 0.248 \\
\hline$\geq 60$ & 17.1 & & 13.3 & \\
\hline \multicolumn{5}{|l|}{ Sex } \\
\hline Male & 17.1 & 0.93 & 13.7 & 0.839 \\
\hline Female & 17.4 & & 14.1 & \\
\hline \multicolumn{5}{|l|}{ Tumor diameter } \\
\hline$<20 \mathrm{~mm}$ & 17.6 & 0.866 & 14.6 & 0.52 \\
\hline$\geq 20 \mathrm{~mm}$ & 17.6 & & 13.9 & \\
\hline \multicolumn{5}{|l|}{ Tumor location } \\
\hline Head & 17.8 & 0.657 & 14.8 & 0.393 \\
\hline Body/tail & 17.4 & & 13.6 & \\
\hline \multicolumn{5}{|l|}{ Serum CAI9-9 } \\
\hline$\leq 37$ & 17.3 & 0.637 & 13.6 & 0.15 \\
\hline$>37$ & 17.6 & & 13.4 & \\
\hline \multicolumn{5}{|l|}{ Histological grade } \\
\hline Moderate/poor & 16.9 & 0.025 & 12.1 & $<0.001$ \\
\hline Well & 19.6 & & 19.2 & \\
\hline \multicolumn{5}{|l|}{ Perineural invasion } \\
\hline Absent & 18.5 & 0.405 & 17.5 & 0.004 \\
\hline Present & 17.2 & & 12.5 & \\
\hline \multicolumn{5}{|l|}{ LNM } \\
\hline Absent & 20.1 & $<0.001$ & 18.6 & $<0.001$ \\
\hline Present & 16.2 & & 10.8 & \\
\hline \multicolumn{5}{|l|}{ TNM stage } \\
\hline 1 & 20.1 & $<0.001$ & 18.6 & $<0.001$ \\
\hline ॥ & 16.2 & & 10.8 & \\
\hline
\end{tabular}

Abbreviations: CAI9-9, carbohydrate antigen 19-9; DFS, disease-free survival; LNM, lymph node metastasis; MICA, major histocompatibility complex class I-related chain A molecules; NKG2D, natural-killer group 2 member D; OS, overall survival; TNM, tumor-node-metastasis.

more prospective investigations with a larger sample size are needed to support our findings.

\section{Conclusion}

Our results show that sMICA is upregulated while NKG2D is downregulated in pancreatic cancer tissues, revealing a significant negative correlation between sMICA expression and NKG2D expression in tumor tissues. High sMICA expression and low NKG2D expression have an unfavorable prognosis, and act as independent prognostic markers for poor DFS and OS in patients with pancreatic cancer. These data provide a strategy for immunotherapy of pancreatic

Table 5 Multivariate analysis of factors associated with OS and DFS

\begin{tabular}{|c|c|c|c|c|c|c|}
\hline \multirow[t]{2}{*}{ Variables } & \multicolumn{3}{|l|}{ DFS } & \multicolumn{3}{|l|}{ OS } \\
\hline & HR & $95 \% \mathrm{Cl}$ & $P$-value & HR & $95 \% \mathrm{Cl}$ & $P$-value \\
\hline Differentiation (moderate/poor vs well) & 1.063 & $0.396-2.849$ & 0.904 & 1.084 & $0.376-3.120$ & 0.882 \\
\hline PNI (absent vs present) & $\mathrm{N} / \mathrm{A}$ & $\mathrm{N} / \mathrm{A}$ & $\mathrm{N} / \mathrm{A}$ & 0.433 & $0.194-0.970$ & 0.042 \\
\hline LNM (absent vs present) & 1.568 & $0.729-3.371$ & 0.250 & 2.124 & $0.977-4.617$ & 0.057 \\
\hline Tumor stage (I vs II) & $\mathrm{I} .568$ & $0.729-3.371$ & 0.250 & 2.124 & $0.977-4.617$ & 0.057 \\
\hline MICA expression (low vs high) & 7.785 & $3.247-18.666$ & $<0.001$ & 3.853 & I.345-II.04I & 0.012 \\
\hline NKG2D expression (low vs high) & 1.862 & $0.663-5.228$ & 0.238 & 0.765 & $0.300-1.949$ & 0.574 \\
\hline
\end{tabular}

Abbreviations: $\mathrm{Cl}$, confidence interval; DFS, disease-free survival; HR, hazard ratio; LNM, lymph node metastasis; MICA, major histocompatibility complex class I-related chain A molecules; NKG2D, natural-killer group 2 member D; OS, overall survival; PNI, perineural invasion; vs, versus; N/A, not available. 
cancer, thereby improving the prognosis of patients with pancreatic cancer.

\section{Acknowledgments}

We thank Dr Lu-Lu Zhai for polishing the manuscript. This study was supported by the National Natural Science Foundation of China (No 81071985).

\section{Disclosure}

The authors report no conflicts of interest in this work.

\section{References}

1. Gong ZH, Holly EA, Bracci PM. Survival in population-based pancreatic cancer patients: San Francisco Bay area, 1995-1999. Am J Epidemiol. 2011;174:1373-1381.

2. Bünger S, Lauber T, Roblick UJ, Habermann JK. Serum biomarkers for improved diagnostic of pancreatic cancer: a current overview. J Cancer Res Clin Oncol. 2011;137(3):375-389.

3. Siegel R, Ma J, Zou Z, Jemal A. Cancer statistics, 2014. CA Cancer JClin. 2014;64(1):9-29.

4. Figueroa JA, Reidy A, Mirandola L, et al. Chimeric antigen receptor engineering: a right step in the evolution of adoptive cellular immunotherapy. Int Rev Immunol. 2015;34(2):154-187.

5. Kim EY, Juvet SC, Zhang L. Regulatory CD4(-)CD8(-) double negative T cells. Methods Mol Biol. 2011;677:85-98.

6. Li W, Tian Y, Li Z, et al. Ex vivo converted double negative T cells suppress activated B cells. Int Immunopharmacol. 2014;20(1):164-169.

7. Dokouhaki P, Schuh NW, Joe B, et al. NKG2D regulates production of soluble TRAIL by ex vivo expanded human $\gamma \delta$ T cells. Eur J Immunol. 2013;43(12):3175-3182.

8. Le Maux Chansac B, Moretta A, Vergnon I, et al. NK Cells infiltrating a MHC Class I-Deficient lung adenocarcinoma display impaired cytotoxic activity toward autologous tumor cells associated with altered NK cell-triggering receptors. J Immunol. 2005;175(9):5790-5798.

9. Chalupny NJ, Sutherland CL, Lawrence WA, Rein-Weston A, Cosman D. ULBP4 is a novel ligand for human NKG2D. Biochem Biophys Res Commun. 2003;305(1):129-135.

10. Kasahara M, Sutoh Y. Comparative genomics of the NKG2D ligand gene family. Immunol Rev. 2015;267(1):72-87.

11. Cai X, Dai Z, Reeves RS, et al. Autonomous stimulation of cancer cell plasticity by the human NKG2D lymphocyte receptor coexpressed with its ligands on cancer cells. PLoS One. 2014;9(10):e108942.

12. Groh V, Wu J, Yee C, Spies T. Tumor-derived soluble MIC ligands impair expression of NKG2D and T-cell activation. Nature. 2002; 419(6908):734-738.

13. Sobin LH, Compton CC. TNM seventh edition: what's new, what's changed: communication from the International Union Against Cancer and the American Joint Committee on Cancer. Cancer. 2010;116(22): 5336-5339.

14. He C, Jiang H, Geng S, et al. Expression and prognostic value of c-Myc and Fas (CD95/APO1) in patients with pancreatic cancer. Int J Clin Exp Pathol. 2014;7(2):742-750.

Therapeutics and Clinical Risk Management

\section{Publish your work in this journal}

Therapeutics and Clinical Risk Management is an international, peerreviewed journal of clinical therapeutics and risk management, focusing on concise rapid reporting of clinical studies in all therapeutic areas, outcomes, safety, and programs for the effective, safe, and sustained use of medicines. This journal is indexed on PubMed Central, CAS,
15. Dambrauskas Z, Svensson H, Joshi M, Hyltander A, Naredi P, Iresjö BM. Expression of major histocompatibility complex class I-related chain $\mathrm{A} / \mathrm{B}$ (MICA/B) in pancreatic carcinoma. Int J Oncol. 2014;4(1):99-104.

16. Cho H, Chung JY, Kim S, et al. MICA/B and ULBP1 NKG2D ligands are independent predictors of good prognosis in cervical cancer. $B M C$ Cancer. 2014;14:957.

17. Agüera-González S, Gross CC, Fernández-Messina L, et al. Palmitoylation of MICA, a ligand for NKG2D, mediates its recruitment to membrane microdomains and promotes its shedding. Eur J Immunol. 2011;41(12):3667-3676.

18. Jia HY, Liu JL, Zhou CJ, et al. High expression of MICA in human kidney cancer tissue and renal cell carcinoma lines. Asian Pac J Cancer Prev. 2014;15(4):1715-1717.

19. Xuan XY, Zhang JF, Hu GM, Li QR, Liu PP, Du Y. Upregulated expression of NKG2D and its ligands give potential therapeutic targets for patients with thymoma. Cancer Gene Ther. 2015;22(7):368-374.

20. Chen D, Gyllensten U. MICA polymorphism: biology and importance in cancer. Carcinogenesis. 2014;35(12):2633-2642.

21. Wang WJ, Qin SH, Zhang JW, Jiang YY, Zhang JN, Zhao L. Combination doxorubicin and interferon- $\alpha$ therapy stimulates immunogenicity of murine pancreatic cancer Panc02 cells via up-regulation of NKG2D ligands and MHC class I. Asian Pac J Cancer Prev. 2014;15(22): 9667-9672.

22. Duan X, Deng L, Chen X, et al. Clinical significance of the immunostimulatory MHC class I chain-related molecule A and NKG2D receptor on NK cells in pancreatic cancer. Med Oncol. 2011;28(2):466-474.

23. Li JJ, Pan K, Gu MF, et al. Prognostic value of soluble MICA levels in the serum of patients with advanced hepatocellular carcinoma. Chin J Cancer. 2013;32(3):141-148.

24. McGilvray RW, Eagle RA, Watson NF, et al. NKG2D ligand expression in human colorectal cancer reveals associations with prognosis and evidence for immunoediting. Clin Cancer Res. 2009;15(22):6993-7002.

25. McGilvray RW, Eagle RA, Rolland P, Jafferji I, Trowsdale J, Durrant LG. ULBP2 and RAET1E NKG2D ligands are independent predictors of poor prognosis in ovarian cancer patients. Int $J$ Cancer. 2010;127(6):1412-1420.

26. Salih HR, Rammensee HG, Steinle A. Cutting edge: down-regulation of MICA on human tumors by proteolytic shedding. J Immunol. 2002; 169(8):4098-4102.

27. Diefenbach A, Jensen ER, Jamieson AM, Raulet DH. Rae1 and H60 ligands of the NKG2D receptor stimulate tumour immunity. Nature. 2001;413(6852):165-171

28. Doubrovina ES, Doubrovin MM, Vider E, et al. Evasion from NK cell immunity by MHC class I chain-related molecules expressing colon adenocarcinoma. J Immunol. 2003;171(12):6891-6899.

29. Young KJ, Kay LS, Phillips MJ, Zhang L. Antitumor activity mediate by double-negative T cells. Cancer Res. 2003;63(22):8014-8021.

30. Dokouhaki P, Han M, Joe B, et al. Adoptive immunotherapy of cancer using ex vivo expanded human gammadelta T cells: a new approach. Cancer Lett. 2010;297(1):126-136.

31. Merims S, Li X, Joe B, et al. Anti-leukemia effect of ex vivo expanded DNT cells from AML patients: a potential novel autologous T-cell adoptive immunotherapy. Leukemia. 2011;25(9):1415-1422. manuscript management system is completely online and includes a very quick and fair peer-review system, which is all easy to use. Visit http://www.dovepress.com/testimonials.php to read real quotes from published authors. 